\title{
Estimating Apple Diameter from Fruit Mass Measurements to Time Thinning Sprays
}

\author{
Richard P. M arini
}

Additional INDEX WORDS. Malus $\times$ domes tica, fruit size

SUmmary. The relationship between fruit mass and fruit diameter for apple fruit 2 to $26 \mathrm{~mm}$ (0.08 to 1.04 inches) in diameter was evaluated for two cultivars sampled from several orchards for three years. A single regression model was appropriate for all combinations of year, cultivar, and orchard. The model was used to develop a chart to quickly estimate fruit diameter from fruit mass. These fruit diameter estimates can be used by commercial fruit growers to time chemical thinner sprays.

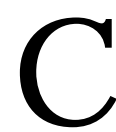

hemical thinners are applied to apple trees to reduce the crop load and improve return bloom, pest control, and fruit quality. In many areas thinners are applied 2 to 3 weeks after full bloom (Greene and Autio, 1989), but in other areas fruit size is used to time thinning sprays(Byersetal., 1995; Pfieffer, 1997). Luckwill (1953a, 1953b) suggested that susceptibility to thinning chemicals might vary with developmental changes in the fruit. Response to chemical thinners apparently is not always influenced by fruit size or days after bloom. Batjer et al. (1968) reported that thinning results did not vary when naphthalene acetic acid (N AA) or carbaryl (Sevin 50 W) was applied at 8 to $21 \mathrm{~d}$ after bloom when fruit diameters averaged 5 to 16 $\mathrm{mm}$ ( 0.2 to 0.65 inches). Their mean separations indicated that the degree of

Department of $\mathrm{H}$ orticulture, Virginia Polytechnic Institute and State U niversity, Blacksburg, VA 24061 0327

The cost of publishing this paper was defrayed in part by the payment of page charges. U nder postal regulations, this paper therefore must be hereby marked advertisement solely to indicate this fact. 
T able 1. Strains of apples sampled from Virginia orchards 1991 and 1992.

\begin{tabular}{lccc}
\hline & & \multicolumn{2}{c}{ Cultivar and strain } \\
\cline { 3 - 4 } Region & Orchard & Delicious & Golden Delicious \\
\hline Central Piedmont & Mt. Cove & Redchief & Smoothee \\
Roanoke Valley & Sprinkle & Redchief & Smoothee \\
Southern Piedmont & Ayers & Redchief & Smoothee \\
N ew River Valley & Redchief & Smoothee \\
& Virginia Tech & Red Prince & \\
& & Starks Spur Supreme & \\
& & Top Red & \\
\hline
\end{tabular}

thinning did not consistently differ for different treatment dates. H owever, therewere trendsin the means that may have been significant had data been analyzed by regression because there would have been more degrees of freedom in the error term. D onoho (1968) and Tukey (1965) found that the efficacy of thinners was related to fruit size. $M$ arini $(1996,1997)$ found that sevin, oxamyl, and NAA thinned moderately at petal fall ( mean fruit diameter $=4.5$ $\mathrm{mm}$ ), but were most effective at 10 to $14 \mathrm{~mm}$, and were not effective at $>18$ $\mathrm{mm}$; ethephon was most effective at $>16 \mathrm{~mm}$. Leuty (1973) found that optimum fruit size for thinning with NAA varied with cultivar. 'D elicious' wasmost sensitive at 6 to $8 \mathrm{~mm}$, 'M cl ntosh' was most sensitiveat 8 to $10 \mathrm{~mm}$ and ' $\mathrm{N}$ orthern Spy at 9 to $10 \mathrm{~mm}$. H owever, benzyladenine thinned ' $E$ mpire' trees similarly when applied from 6 to $29 \mathrm{~d}$ after bloom (E Ifving and Cline, 1993).

$M$ any commercial apple growers in the mid-Atlantic region use fruit diameter to timethinning sprays. Because measuring individual fruit with calipers is expensive, afaster method to measure fruit size is needed. This study was undertaken to determine if fruit mass could be used to estimate the diameters of fruit from different orchards and cultivars for timing thinning sprays.

\section{Materials and methods}

$D$ ata for this study were collected in 1991 and 1992 for 'SmootheeG olden Delicious' and four strains of 'D elicious', and fruit were sampled from several orchards located in central and southern Virginia (Table 1). Each year treesof 'Smoothee' and 'C ampbell Redchief Delicious', growing in two orchards (Ayers and Virginia T ech), were sampled three or four times to provide fruit diameters ranging from $\approx 4$ (petal fall) to $26 \mathrm{~mm}$ (0.16 to 1.04 inches), and in 1992 fruit were sampled once from two additional commercial or- chards. Four other strains of 'D elicious' were sampled once from the Virginia Tech orchard. These single sampling dates provided samples with fruit diameters ranging from about 6 to $16 \mathrm{~mm}$. On each date two fruiting spurs, having one or more fruit, were harvested from each of 15 trees. Spurs were defoliated, sealed in zip-lock plastic bags, and transported on ice in coolers to the laboratory. The maximum diameter of each fruit was measured with calipers and each fruit, with pedicel attached, was weighed. About 50 fruit per sample, varying from the largest to the smallest fruit that appeared as if they would not abscise, were measured.

Model BUILDING. The relationship between fruit diameter (FD) and fruit mass (FM) for 'Redchief D elicious' was evaluated by fitting various polynomial regression modelswith the REG Procedure of SAS (Freund and Littell, 1991). Fruit diameter was the dependent variableand the independent variableswere $\mathrm{FM}, \mathrm{FM}^{-1 / 2}, \mathrm{FM}^{-1 / 3}$, and $\mathrm{FM}^{-1 / 4}$. All 14 possiblecombinationsof thesefour variables were evaluated with the Rsquare option of the REG Procedure. Criteria used to select the best model included the coefficient of determination $\left(R^{2}\right)$, adjusted $R^{2}, M$ allow's conceptual predictive criteria $(C p)$, mean square error (M SE) and the prediction sum of squares (PRESS). Residualswereanalyzed to check for the presence of outliers, nonconstant error variance and omission of important predictor variables. The best model was $F D=F M-F^{-1 / 3}$. Analysis of covariance wasthen performed with the GLM Procedure of SAS (Littell et al., 1991) to test equality of models for different orchards, strains, and years. O ne of the categorical variables (orchard, strain, or year) was included as the indicator or dummy variable and $\mathrm{FM}$, the continuous variable, was included as the covariate. Type III sums of squares were used to evaluate the significance of the indicator variable and interaction terms in- volving the indicator variable (for example, location $\times F M$ and location $x$ $\left.\mathrm{FM}^{-1 / 3}\right)$. Because theindicator variables (orchard, strain, and year) and the two interaction terms containing indicator variables were not significant $(p>0.05$ ) for each indicator variable, all 'D elicious' data were pooled to develop a single model to estimate FD from FM. The same approach resulted in a single model for 'Smoothee'. Analysis of covariance also indicated that models for 'D elicious' and 'Smoothee' did not differ significantly $(p>0.05)$. Therefore, data from all locations and strains for 1991 and 1992 were pooled (referred to as the estimation data set) to develop a single model that will be referred to as the estimation model.

Model validation. To validate the estimation model, 120 'Smoothee' and 60 'C ampbell Redchief D elicious' fruit were collected from the Virginia Tech orchard in 1997 to developed a new data set (validation data set). T wo techniques were then used to validate the fitting model. 1) The validation dataset wasused to produce a validation model by reestimating the model parameters using the all-possible regressions approach used to develop the estimation model and the two models were compared for consistency. 2) Theregression parameter estimates from the estimation model were then used to predict outcomesfor observationsin the validation data set (M ontgomery and Peck, 1992). Because both techniques indicated that predictiveperformance of the estimation model appeared reasonably good, the final estimation of parameters was accomplished by pooling data from all three years (referred to as the entire data set) to develop the entire model (M yers, 1990).

\section{Results and discussion}

Regression modelsfor several combinations of year, location, and strain are presented in Table 2 to provide 
T able 2. Regression models relating fruit diameter (FD) to fruit mass (FM) for several strains of 'D elicious' apple sampled from several apple orchards during 2 years.

\begin{tabular}{|c|c|c|c|c|c|c|c|}
\hline \multirow[b]{2}{*}{ Year } & \multirow[b]{2}{*}{ Strain $^{y}$} & \multirow[b]{2}{*}{ Orchard ${ }^{\mathrm{x}}$} & \multicolumn{3}{|c|}{$\begin{array}{c}\text { Coefficient } \\
\text { (sE of estimate) }\end{array}$} & \multicolumn{2}{|c|}{ M odel $^{z}$} \\
\hline & & & I ntercept & FM & $F M^{-1 / 3}$ & $\mathbf{N}$ & $\mathbf{R}^{2}$ \\
\hline 1991 & $\mathrm{RC}$ & $\begin{array}{l}A \\
M \\
S \\
V\end{array}$ & $\begin{array}{c}18.76(1.31) \\
7.07(3.34) \\
36.25(3.64) \\
9.99(2.61)\end{array}$ & $\begin{array}{l}1.23(0.32) \\
5.69(2.40) \\
0.32(0.14) \\
3.65(0.99)\end{array}$ & $\begin{array}{l}-8.88(0.96) \\
-2.00(1.73) \\
-31.61(4.98) \\
-3.26(1.69)\end{array}$ & $\begin{array}{r}140 \\
50 \\
50 \\
28\end{array}$ & $\begin{array}{l}0.92 \\
0.84 \\
0.95 \\
0.93\end{array}$ \\
\hline 1992 & $\begin{array}{l}\text { RP } \\
\text { SS } \\
\text { TR }\end{array}$ & $\begin{array}{l}A \\
M \\
V \\
V \\
V \\
V\end{array}$ & $\begin{array}{c}14.35(0.21) \\
7.94(3.42) \\
17.72(0.48) \\
17.58(1.52) \\
15.43(1.01) \\
20.32(1.96)\end{array}$ & $\begin{array}{l}1.94(0.05) \\
5.61(3.11) \\
1.46(0.06) \\
1.48(0.33) \\
1.71(0.23) \\
0.84(0.44)\end{array}$ & $\begin{array}{l}-5.99(0.13) \\
-2.90(1.64) \\
-8.59(0.42) \\
-8.35(1.16) \\
-6.82(0.75) \\
-10.67(1.51)\end{array}$ & $\begin{array}{r}300 \\
36 \\
177 \\
50 \\
50 \\
50\end{array}$ & $\begin{array}{l}0.99 \\
0.80 \\
0.98 \\
0.96 \\
0.97 \\
0.94\end{array}$ \\
\hline
\end{tabular}

${ }^{z A}$ ll models are significant $(P<0.0001)$.

$\mathrm{y}_{\mathrm{RC}}=$ Redchief; RP = Red Prince; SS = Starks Spur Supreme; TR = Top Red.

${ }^{\mathrm{x}} \mathrm{M}=\mathrm{M}$ t. Cove, $\mathrm{S}=$ Sprinkle, $\mathrm{A}=$ Ayers, $\mathrm{V}=$ Virginia Tech.

readerswith theopportunity to evaluate thesimilarity of themodels. For eight of the 10 models, the $R^{2}>0.9$ and, except for 'Redchief D elicious' sampled from Sprinkle Orchard in 1991, parameter estimates and standard errors of the estimates were similar. No explanation can be offered as to why data from Sprinkle O rchard differ from data from other orchards.

Parameter estimates and statistics from SAS output are presented for the estimation, validation, and entire models ( $T$ able 3 ). The parameter estimates and $R^{2}$ values are similar for the estimation and validation models, providing some assurance about the applicability of the estimation model to data beyond those on which the model is based ( $N$ eter et al., 1996).

Analysis of residuals is an important technique for evaluating the fit of regression models. The residual for a given observation is defined as the difference between the observed and fitted value. When plotted against the observed values of a response variable, the residuals for a good model are distributed randomly and normally in a horizontal band centered around zero ( $\mathrm{N}$ eter et al., 1996). These residuals are measures of quality of how a model fits the data that were used to develop it, but they do not assess quality of future prediction. A model that fits the data well may not be good for predicting future observations. The least squares procedureis designed to produce propertiesin the regression function that will result in residuals that are smaller than true prediction errorsand do not generally indicate how the regression model will predict (M yers, 1990). Because the model developed in this study will be used to predict fruit diameter from fruit mass, it is critical to investigate the model'spredictiveperformance. Forvalidation, the estimation regression model was used to predict outcomes for an independent set of data; data that were not used to estimate the model parameters (validation data set) ( $M$ ontgomery and Peck, 1992; $M$ yers, 1990; $N$ eter et al., 1996). If the model is a good predictor, the prediction errors (the difference between the observed and predicted values) should be similar in magnitude and distribution to the residuals for the data (estimation data) used to estimate the model parameters. This was the case for the val idation data set (Fig. 1). Additionally, the predicted valuesfor fruit diameter from the validation data set were similar to the observed values (Fig. 2).

A means of measuring the actual

T able 3. Statistics and parameters estimated from regression models developed from three data sets. The estimation model was developed using fruit of several strains of 'D elicious' and ' $G$ olden D elicious' collected from several locations in 1991 and 1992. The validation model was developed from 'D elicious' and 'Smoothee' fruit sampled in 1997. The complete model was developed by combining the estimation and validation data sets.

\begin{tabular}{lccr}
\hline $\begin{array}{l}\text { Statistic or } \\
\text { parameter } \\
\text { estimate }\end{array}$ & $\begin{array}{c}\text { Estimation } \\
\text { model }\end{array}$ & $\begin{array}{c}\text { Validation } \\
\text { model }\end{array}$ & $\begin{array}{r}\text { Entire } \\
\text { model }\end{array}$ \\
\hline Intercept estimate & 16.791 & 19.1258 & 17.1964 \\
Standard error of intercept & 0.1086 & 0.5548 & 0.1051 \\
Regression coefficient for FM & 1.457 & 1.1171 & 1.3572 \\
Standard error for FM & 0.0194 & 0.0522 & 0.0166 \\
Regression coefficient for FM $-1 / 3$ & -7.579 & -9.3643 & -7.8247 \\
Standard error for FM $-1 / 3$ & 0.0754 & 0.4886 & 0.0751 \\
Error sums of squares & 653.645 & 169.9560 & 860.1743 \\
Prediction sum of squares & 659.008 & --.9602 & 865.300 \\
M ean square error & 0.4639 & 1.2724 & 0.5413 \\
M ean of the squared prediction errors & --- & 0.9677 & -- \\
Coefficient of determination & 0.9796 & 179 & 0.9788 \\
Total degrees of freedom & 1411 & & 1590
\end{tabular}

FM = fruit mass $(\mathrm{g})$. 

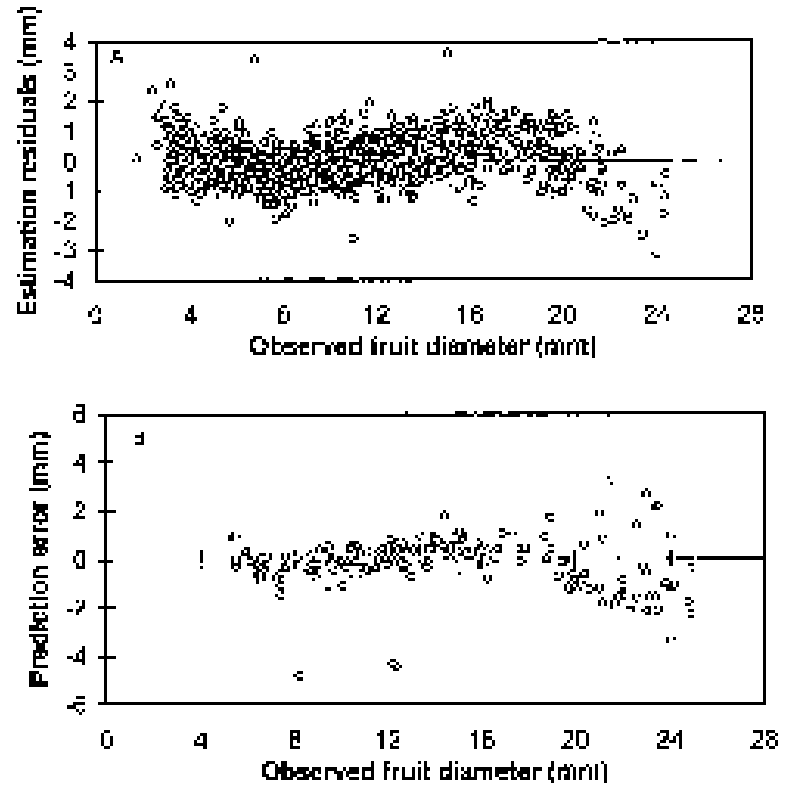

indication of the predictive ability of the model. In this case, the M SPR from the validation data set (1.27) does not differ too greatly from the MSE of the estimation data set $(0.46)$. This implies that the MSE based on the estimation data set is a reasonably valid indicator of the predictive ability of the estimation regression model ( $N$ eter et al., 1996).

The PRESS criterion is a measure of how well the use of the fitted valuesfor asubset model can predict theobserved values of the response

Fig. 1. Comparison of regression residuals and predicted errors from validation of the estimation model. (A) D ata are from the estimation data set. The regression residual was defined as the actual value minus the fitted value. (B) Data are from the validation data set. 0 utcomes were predicted using parameter estimates obtained from the estimation data set. Prediction error was defined as the actual value minus the predicted outcome.

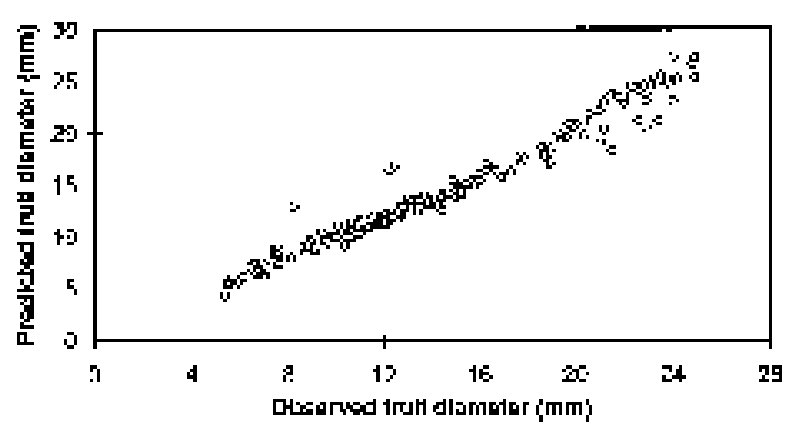

Fig. 2. Performance of the model parameter estimates obtained from the estimation data set to predict fruit diameter from the validation data set.

predictive capability of the estimation regression model is to use this model to predict each case in the validation data set and then to calculate the mean of the squared prediction errors (M SPR). If the M SPR is fairly close to the MSE based on the regression fit to theestimation data set, then the MSE for the selected regression model is not seriously biased and gives an appropriate variable $Y$. The error sum of squares (SSE) isal so such ameasure. ThePRESS measure differs from SSE in that each fitted value for the PRESS criterion is obtained by deleting the $i^{\text {th }}$ case from the data set. The regression function is estimated for the subset model from the remaining $n-1$ cases, and then the fitted regression function is used to obtain the predicted value of $Y$ for the $i^{\text {th }}$ case. PRESS was calculated for the models developed from the estimation dataand theentiredataset bysumming the squared prediction errors (the difference between theobserved and predicted fruit diameter when one observation is deleted). Some evidence of the internal validity of thefitted model isto comparePRESSand SSE. The PRESS value is always larger than SSE because theregression fit for the $i^{\text {th }}$ case when this case is deleted in fitting can never be asgood as that when the $i^{i \text { th }}$ case is included. A PRESS value reasonably close to SSE, as here (for the estimation model PRESS $=659.0$, SSE = 653.6; for the entire model PRESS = 865.3, SSE =860.2), supports the validity of the fitted regression modelsand of the MSEs as an indicator of the predictive capability of these models (N eter et al., 1996).

The PRESS residuals can be used to generate another $\mathrm{R}^{2}$-likestatistic that reflects prediction capabilities ( $M$ yers, 1990). For the model developed from the entire data set, this statistic is calcu- lated as $\mathrm{R}^{2}$ red $=1$ - (PRESS/ total sums of squares $) \stackrel{\text { pred }}{=} 1-(865.3 / 40657.8)=$ 0.9787 . Thuswemightexpect themodel developed from the entire data set to explain $\approx 97.9 \%$ of the variability explained by the least squares fit to the estimation data set. The loss in $\mathrm{R}^{2}$ $(0.9788$ vs. 0.9787$)$ is very small, so there is reasonably strong evidence that theleast squaresmodel will bea satisfactory predictor.

Results from model validation indicate that the model developed from the entire data set is a good predictive model to predict fruit diameter from fruit mass for 'Golden Delicious' and 'D elicious' strainsgrown in commercial orchardsin Virginia. The predicted line from the regression model developed from theentire dataset (Fig. 3) wasused to develop a chart to be used by fruit growers to estimate FD from a sample of 100 fruit (Table4). M ost commercial growers do not have equipment to accurately weigh individual fruit, but most should be able to accurately weigh a sample of 50 to 100 fruit. Fruit mass values in Table 4 are reported in grams, ounces, and poundsbecause thistableis intended to be used by growers, many of whom use English units.

Efficacy of thinning chemicalsmay be related to the distribution of fruit sizes on the tree (unpublished data) as well as the mean fruit size. U nfortu-

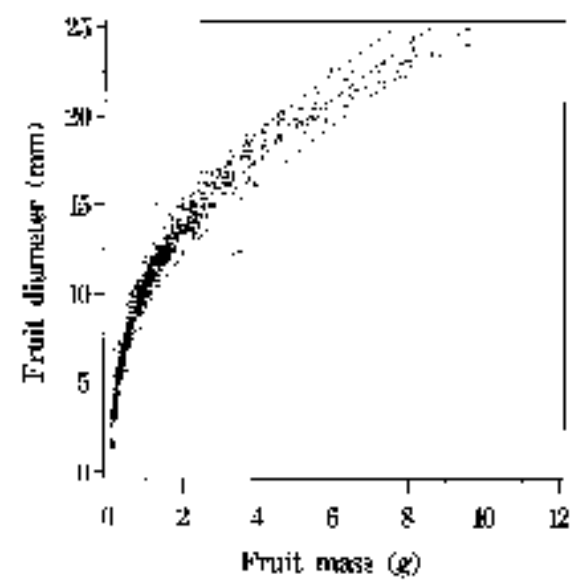

Fig. 3. Scatter plot and predicted line with the $95 \%$ prediction interval for a single observation showing the relationship between apple fruit mass (FM) and fruit diameter (FD). Data include 'Smoothee G olden Delicious' and four strains of 'D elicious' sampled from four orchards during 1991, 1992, and 1997 (entire data set). $R$ egression model: FD = 17.2 + $1.36 \mathrm{FM}-7.82 \mathrm{FM}^{-1 / 3} ; n=1593, R^{2}=$ 0.979 , model $\mathrm{p}<0.0001$. 
T able 4. Apple diameter estimated from apple mass.

\begin{tabular}{|c|c|c|c|c|c|}
\hline \multicolumn{2}{|c|}{$\begin{array}{l}\text { Single } \\
\text { fruit } \\
\text { mass }\end{array}$} & \multicolumn{3}{|c|}{$\begin{array}{l}100 \\
\text { Fruit } \\
\text { mass }\end{array}$} & \multirow{2}{*}{$\begin{array}{l}\text { Mean } \\
\text { fruit } \\
\text { diam } \\
(\mathrm{mm})\end{array}$} \\
\hline (g) & $(0 z)$. & (g) & (oz.) & (Ib) & \\
\hline 0.15 & 0.005 & 15 & 0.530 & 0.033 & 2.67 \\
\hline 0.2 & 0.007 & 20 & 0.706 & 0.044 & 4.09 \\
\hline 0.25 & 0.009 & 25 & 0.883 & 0.055 & 5.12 \\
\hline 0.3 & 0.011 & 30 & 1.059 & 0.066 & 5.92 \\
\hline 0.4 & 0.014 & 40 & 1.412 & 0.088 & 7.12 \\
\hline 0.5 & 0.018 & 50 & 1.765 & 0.110 & 8.02 \\
\hline 0.7 & 0.025 & 70 & 2.471 & 0.154 & 9.33 \\
\hline 0.9 & 0.032 & 90 & 3.177 & 0.199 & 10.31 \\
\hline 1.1 & 0.039 & 110 & 3.883 & 0.243 & 11.11 \\
\hline 1.3 & 0.046 & 130 & 4.589 & 0.287 & 11.79 \\
\hline 1.6 & 0.056 & 160 & 5.648 & 0.353 & 12.68 \\
\hline 2 & 0.071 & 200 & 7.060 & 0.441 & 13.70 \\
\hline 2.4 & 0.085 & 240 & 8.472 & 0.530 & 14.61 \\
\hline 2.8 & 0.099 & 280 & 9.884 & 0.618 & 15.44 \\
\hline 3.3 & 0.116 & 330 & 11.649 & 0.728 & 16.42 \\
\hline 3.9 & 0.138 & 390 & 13.767 & 0.860 & 17.52 \\
\hline 4.5 & 0.159 & 450 & 15.885 & 0.993 & 18.56 \\
\hline 5.2 & 0.184 & 520 & 18.356 & 1.147 & 19.74 \\
\hline 5.9 & 0.208 & 590 & 20.827 & 1.302 & 20.87 \\
\hline 6.8 & 0.240 & 680 & 24.004 & 1.500 & 22.29 \\
\hline 7.7 & 0.272 & 770 & 27.181 & 1.699 & 23.68 \\
\hline 8.7 & 0.307 & 870 & 30.711 & 1.919 & 25.20 \\
\hline 9.7 & 0.318 & 900 & 31.770 & 1.986 & 25.65 \\
\hline 10.7 & 0.378 & 1070 & 37.771 & 2.361 & 28.17 \\
\hline
\end{tabular}

nately, weighing a sample of fruit and using Table 4 will provide no information concerning the distribution of fruit sizes.

Because fruit shape (length to diameter ratio) is influenced by temperature (Westwood, 1993) and the application of growth regulators (Bukovac and Nakagawa, 1968), this model may not be adequate for all situations in Virginia. H owever, because there is a fairly large window within which thinning treatments are effective (Donoho, 1968; M arini, 1996), the model may be robust enough to provideFD estimateswith acceptableaccuracy for commercial fruit growers. Fruit shape also varies with cultivar. Different models will likely need to be developed fornonconiccultivars. O bservationsthat susceptibility to thinning chemical s varies with fruit development, along with the assumption that fruit size better estimates fruit development than days after bloom, led to the practice of using fruitsizeto timethinning sprays(T ukey, 1965). Cultural practices or growing conditions may influence fruit shape more than fruit development. Therefore, FM may actually be the better measure of fruit development. U nfortunately, many researchers report mean FD at the time of thinning application, but few report FM. To develop a data base, and to test the validity of using FM to time thinning sprays, it would be beneficial if in the future researchers would report days after full bloom, as well asFD and FM at thetime of thinner application.

Fruit sizeisonly onecomponent of thinning efficiency. Cultivar, choice of surfactant and environmental conditions for several days after treatment also can influence thinning. M ore research is needed to understand these other factors and the possible interactions of these factors with fruit size.

\section{Literature cited}

Batjer, L.P., C.G. Forshey, and M.B. $\mathrm{H}$ offman. 1968. E ffectiveness of thinning sprays as related to fruit size at time of spray application. Proc. Amer. Soc. H ort. Sci. 92:50-54

Bukovac, M.J. and S. N akagawa. 1968. Gibberellin-induced asymmetric growth of apple fruits. H ortScience 3:172-174.

Byers, R.E., C.S. Walsh, L.M. Ingle, S. Altman, and K. H unt. 1995. Pollination, fertilization and set, p. 187-194. In: H.W. Hogmire, Jr. (ed.). M id-Atlantic orchard monitoring guide. NE Reg. Agr. Eng. Service. I thaca, N.Y.
Donoho, C.W. 1968. The relationship of date of application and size of fruit to the effectiveness of NAA for thinning apples. Proc. Amer. Soc. H ort. Sci. 92:55-62.

Elfving, D.C. and R.A. Cline. 1993. Benzyladenine and other chemicals for thinning 'Empire' apple trees. J. Amer. Soc. H ort. Sci. 118:593-598.

Freund, R.J. and R.C. Littell. 1991. SAS system for regression. SAS Inst. Inc., Cary, N.C.

Greene, D.W. and W.R. Autio. 1989. Evaluation of benzyladenine as a chemical thinner on 'M cl ntosh' apples. J. Amer. Soc. H ort. Sci. 114:68-73.

Leuty, S.J. 1973. Identification of maximum sensitivity of developing apple fruitsto naphthaleneacetic acid. J. Amer. Soc. H ort. Sci. 98:247-252.

Littell, R.C., R.J . Freund, and P.C. Spector. 1991. SAS system for linear models. SAS Inst. Inc., C ary, N.C.

Luckwill, L.C. 1953a. Studies of fruit development in relation to plant hormones. I. $\mathrm{H}$ ormone production by the developing apple seed in relation to fruit drop. J. H ort. Sci. 28:14-24.

Luckwill, L.C. 1953b. Studiesof fruit development in relation to plant hormones. II. Theeffect of naphthaleneacetic acid on fruit set and fruit development in apples. J. H ort. Sci. 28:25-40.

Marini, R.P. 1996. Chemically thinning spur 'D elicious' apples with carbaryl, NAA, and ethephon at variousstages of fruit development. H ortT echnology 6:241-246.

M arini, R.P. 1997. Oxamyl is an effective apple fruit thinner when used al one or when combined with other thinners. H ortT echnology 7:253-258.

Montgomery, D.C. and E.A. Peck. 1992. Introduction to linear regression analysis. 2nd ed. Wiley, N ew York.

M yers, R.H. 1990. Classical and modern regression with applications. 2nd ed. PWSKent, Boston.

N eter, J., M.H. Kutner, C.J. N achtshein, and W. Wasserman. 1996. Applied linear statistical models. 4th ed. I rwin, H omewood, III.

Pfeiffer, D.G. 1997. 1997. Virginia, West Virginia and $M$ aryland commercial treefruit spray bulletin. VCE Publ. 456-419.

Tukey, L.D. 1965. Fruit-size in chemical thinning of appletrees. Trans. III. H ort. Soc. 99:67-79.

Westwood, M.N. 1993. Temperate-zone pomology physiology and culture. Timber Press. Portland, Ore. 